\title{
Neighbourhood social environment and depressive symptoms in mid-life and beyond
}

\author{
MAI STAFFORD*, ANNE MGMUNN $\dagger$ and ROBERTO DE VOGLI $\dagger$
}

\begin{abstract}
This prospective study examines the relationship between aspects of the neighbourhood social environment and subsequent depressive symptoms in over 7,500 participants of the English Longitudinal Study of Ageing (ELSA). Neighbourhood social environment at baseline was operationalised using four items capturing social cohesion and three items capturing perceived safety and associations with the Center for Epidemiologic Studies Depression Scale (CES-D) at two-year follow-up were assessed. Friendship quality and personal sense of control were tested as mediators of this relationship using structural equation modelling. Neighbourhood social cohesion was found to be associated with reporting fewer depressive symptoms independent of demographic and socioeconomic factors and baseline depressive symptoms. Friendship quality and sense of control mediated this association. The study highlights that greater personal sense of control, higher quality friendships and fewer depressive symptoms are found in neighbourhoods seen to be characterised by higher social cohesion.
\end{abstract}

$\boldsymbol{K E Y} \boldsymbol{W} \boldsymbol{W} \boldsymbol{D} \boldsymbol{S}$ - friends, friendship quality, sense of control, neighbourhood, prospective study.

\section{Introduction}

Depression is a major contributor to disability (Murray and Lopez I996) and is a common reason for primary care consultation (Shah I992). Recent estimates of depression prevalence among the over 5 os in Europe range from around i7 to 36 per cent (Castro-Costa et al. 2007). The social precursors of depressive symptoms are socioeconomically patterned (Brown and Harris I978) and include those which increase susceptibility to depression (such as chronic stressors and chronic health conditions) and those which are protective or buffer against depression (such as social relationships and social support (House, Landis and Umberson i988). The neighbourhood social environment may be a setting which exposes people

* MRC Unit for Lifelong Health and Ageing, London, UK.

$\dagger$ Department of Epidemiology and Public Health, University College London, UK. 
to factors that can be either beneficial or harmful for depression. Recent studies indicate concepts such as neighbourhood social capital and social cohesion are associated with depressive symptoms in the general population (Almedom 2005; De Silva et al. 2005; Xue et al. 2005) and the neighbourhood environment is potentially of greater importance among older compared with younger adults (Laporte, Nauenberg and Shen 2007). Over the lifecourse, people become attached to their neighbourhood and to their home (Rubinstein and Parmelee 1992; Sampson I988; Scharf, Phillipson and Smith 2003) and perform most of their daily activities there (Baltes et al. I999). This attachment can develop through increased length of residence which can contribute to a sense of familiarity and security (Lawton I990) and because of the experiences which have taken place there and contribute to a person's identity (Shenk, Kuwahara and Zablotsky 2004).

Various pathways linking the neighbourhood social environment to depressive symptoms have been theorised (Kawachi and Berkman 2001 $a$; Scheffler, Brown and Rice 2007). These include the potential for providing psychological support and guidance to aid coping with difficulties and protect against depressive symptoms and providing a sense of purpose and belonging that may directly influence psychological wellbeing. Empirical investigation of these pathways is limited. This study explores the association between two components of the neighbourhood social environment, namely social cohesion and perceived safety, and depressive symptoms, and the aim is to elucidate explanatory mechanisms linking these among older adults.

\section{Neighbourhood social cohesion and perceived safety}

Neighbourhood social cohesion refers to norms of trust, solidarity and reciprocity, which have been extensively studied in relation to depression in children (Xue et al. 2005), the general population (Almedom 2005; Aneshensel and Sucoff i996; Boreham, Stafford and Taylor 2002; De Silva et al. 2005; Ellaway, Macintyre and Kearns 2001; Elliott 2000; Pevalin and Rose 2003; Phongsavan et al. 2006; Ross 2000) and specifically in older adults (Cannuscio, Block and Kawachi 2003; Keating, Swindle and Foster 2005; McMunn et al. 2009; Pollack and von dem Knesebeck 2004; Schieman and Meersman 2004). Another aspect of the neighbourhood social environment that has received attention in relation to depressive symptoms is that of social disorder (Kim 2008), encapsulating for example worry about crime (Martin et al. 2010; Roman and Chalfin 2008; Stafford, Chandola and Marmot 2007) and incivilities such as graffiti and litter (Ellaway et al. 2009; Sampson, Raudenbush and Earls 1997). Neighbourhood social disorder is theorised to signal lack of care amongst residents and local authorities and can lead to a downward spiral 
of increasing disorder, antisocial behaviour and crime (Wilson and Kelling I982). The focus of the present study is on perceived safety and incivilities, hereon referred to as perceived safety.

Previous studies have used various methods to capture neighbourhood social cohesion and perceived safety including participant's individual perceptions and perceptions aggregated over residents located in the same small area. The approach taken in the present study is to use individual perceptions because aggregate data would require larger numbers of participants in each neighbourhood than were available here. This choice of methodology is discussed later.

\section{Pathways linking the neighbourhood social environment to depressive symptoms}

Greater levels of neighbourhood-based social cohesion may be associated with lower prevalence of depressive symptoms through higher-quality social interactions with people in the neighbourhood (Berkman et al. 2000; Kawachi and Berkman 2001 $b$; Scheffler, Brown and Rice 2007; Szreter and Woolcock 2004). Living in a cohesive neighbourhood may support interpersonal connections which provide health-promoting information. In residential environments where norms of trust and reciprocity abound, it is expected that relationships between friends and neighbours would be characterised by positive rather than negative social exchanges. Positive aspects of social relations at the individual level (including greater perceived emotional and instrumental support) have been associated with lower risk of depressive symptoms (Boreham, Stafford and Taylor 2002; Lin, Ye and Ensel 1999; Stansfeld and Candy 2006; Stansfeld, Fuhrer and Shipley 1998; Van der Horst and McLaren 2005) and negative aspects of social relations have been associated with higher risk of depressive symptoms (Hobfoll and Stephens 1990; Ingersoll-Dayton, Morgan and Antonucci 1997; Rauktis, Koeske and Tereshko 1995) although the temporal sequence is complex (Fyrand et al. 2002).

Greater social cohesion and perceived safety may also induce a greater sense of control or reduce a sense of powerlessness amongst residents as they recognise their roles in effecting change in their neighbourhood (Hawe and Shiell 2000; Ross 2000). Perceived control is understood as a sense of self-determination - an ability to actively intervene in one's environment (Rodin I986) and has been linked to lower rates of depressive symptoms (Chou 2005; Keeton, Perry-Jenkins and Sayer 2008; Ross and Mirowsky 2006; Steptoe et al. 2007; Yang 2006). On the other hand, greater social cohesion could diminish personal freedom of choice in some instances (Portes 1998) and so the relationship of personal sense of control to neighbourhood social cohesion remains a question to address empirically. 
Our empirical model tests these two proposed pathways linking social cohesion and perceived safety to depressive symptomatology. The norms of trust, solidarity and reciprocity which make up neighbourhood social cohesion might enable residents to develop and maintain more supportive friendships. Conversely, a lack of neighbourhood cohesion might increase a resident's experiences of negative aspects of friendships within that community. In addition, weaker social cohesion and lower perceived safety may reduce residents' personal sense of control.

\section{Study aims}

The aims of this study are twofold. Using longitudinal data from a general population of adults aged 50 and over, we describe the relationships of neighbourhood-based social cohesion and perceived safety with depressive symptoms. We then assess the extent to which the quality of friendships and personal sense of control mediate the relationship between neighbourhood social cohesion/perceived safety and depressive symptoms.

\section{Methods}

\section{The English Longitudinal Study of Ageing}

The data for this study come from the English Longitudinal Study of Ageing (ELSA) study. ELSA is a sample of people aged 50 and older living in England. ELSA was drawn from a general population sample of households that responded to the Health Survey for England (HSE) in I998, I999 and 200I. The HSE uses a multi-stage clustered sampling design, stratified by region and socioeconomic characteristics, to select households and residents (Erens and Primatesta 1999). ELSA therefore provides a sample representative of community living over 5 os in England. Individuals were classified as core ELSA sample members at wave I if they were included in the HSE and were aged 50 in $2002-03$ when the first wave of ELSA took place. At wave I, of the 17,744 eligible HSE sample members, 648 had died, moved outside of England or into an institution. A total of II,392, 67 per cent of eligible sample members, took part in wave I of ELSA. Of these, 8,78 I (82 per cent) also participated in the second wave (in 2004-05). More detail on the sampling and response rates for ELSA are given elsewhere (Taylor et al. 2003). Here we use data on the neighbourhood social environment and quality of social relations at wave I to predict the number of depressive symptoms at wave 2. Data were accessed through the Economic and Social Data Service. Ethical 
clearance for the study was obtained from the Multicentre Research and Ethics Committee.

\section{Depressive symptoms, friendships, sense of control and perceived neighbourhood}

All data were collected by face-to-face interviews conducted in the participant's home, except for measures of perceived neighbourhood environment, quality of friendships and sense of control which were collected in a self-completion booklet. Depressive symptoms were measured at waves I and 2 using an eight-item version of the Center for Epidemiologic Studies Depression Scale (CES-D). This tool has been validated against the full CES-D (Turvey, Wallace and Herzog I999) and used in community settings to predict mortality (Turvey et al. 2009).

Items capturing quality of friendships were included at wave I. Participants were asked if they had any friends. For the 93 per cent who reported that they did, a further six items captured positive and negative aspects of those friendships: 'How much do they understand the way you feel about things?', 'How much can you rely on them?', 'How much can you open up to them?', 'How much do they criticise you?', 'How much do they let you down?' and 'How much to they get on your nerves?' Possible responses were scored from o ('not at all') to 3 ('a lot').

Four items thought to capture personal sense of control were included at wave I. These items were taken from the CASP-I9 - a tool which captures quality of life on four domains (control, autonomy, self-realisation and pleasure) in older people (Hyde et al. 2003). Possible responses to the following items were scored from o ('often') to 3 ('never'): 'My age prevents me from doing the things I would like to', 'I feel that what happens to me is out of my control', 'I feel free to plan for the future', 'I feel left out of things'.

Seven items captured elements of the neighbourhood social environment at wave I. A priori, five were thought to capture neighbourhoodbased social cohesion and two were thought to capture perceived safety. However, goodness-of-fit indices indicated that an item capturing whether people in the area would help if you were in trouble was more closely related to perceived safety than to social cohesion (see Table 2 for item descriptions). Possible responses ranged from i to 7 (the latter indicating greatest agreement with the statement). It should be noted that these items capture individual perceptions of the neighbourhood social environment. Ideally, we would have used neighbourhood-level data but this was not available from external sources and although ELSA participants are geographically clustered into primary sampling units, 
there are insufficient numbers per area to aggregate data in a meaningful way.

\section{Other covariates}

Four categories of employment status were derived to capture being in paid employment, retired or semi-retired, home makers, and unemployed or long-term sick. Total wealth (including housing and non-housing wealth but excluding pension wealth) was assessed using a battery of items (Banks, Karlsen and Oldfield 2003) and analysed as quintiles. Marital status was analysed as married or cohabiting versus never married, separated or widowed.

\section{Statistical methods}

Descriptive statistics were weighted for the multi-stage sampling design and non-response based on known probability of sampling. Neighbourhood social cohesion, perceived safety, positive and negative aspects of friendships and personal sense of control were analysed as latent variables. To assess whether the observed data were consistent with each latent construct, goodness-of-fit indices were calculated. A latent variable model with three or fewer items capturing one factor is not identifiable and so latent variables were tested pair-wise and in other combinations but only the final measurement model including all $\mathrm{i} 7$ items capturing five latent constructs is presented (Table 2). In this model, each latent variable is correlated with all others and no structure is imposed on the relationships between latent variables. The Standardised Root Mean Squared Residual (SRMR), the Root Mean Square Error of Approximation (RMSEA) and the Tucker-Lewis index (TLI) are presented as they are appropriate for larger sample sizes and have been shown to provide complimentary information on goodness of fit under different model scenarios using the following cut-offs: SRMR $<0.08$, RMSEA $<0.06$ and TLI $>0.95$ (Hu and Bentler I999).

The associations between number of depressive symptoms at wave 2 and the latent variables capturing the neighbourhood social environment at wave I were assessed using a structural equation model, controlling for gender, age, employment status, total wealth, marital status and depressive symptoms at previous wave. To this initial structural model, we added personal sense of control and positive and negative aspects of friendships to investigate their role as mediators. Analyses were undertaken in MPlus using maximum likelihood estimation and including participants who provided any pair-wise covariances (resulting in the exclusion of $3^{8}$ participants). 
T A B L E I. Wave I (2002-03) demographic characteristics and health at two-year follow-up for participants aged 50 and over in the English Longitudinal Study of Ageing

\begin{tabular}{|c|c|c|}
\hline $\begin{array}{l}\text { Demographic characteristics } \\
\text { at wave I }(2002-03)\end{array}$ & $\begin{array}{l}\text { Number (weighted \%) } \\
\text { of participants }\end{array}$ & $\begin{array}{c}\text { Weighted mean (SD) } \\
\text { number of depressive } \\
\text { symptoms at wave } 2 \\
(2004-05)\end{array}$ \\
\hline \multicolumn{3}{|l|}{ Gender $\dagger$} \\
\hline Male & $5^{187}(46)$ & I.3 (I.8) \\
\hline Female & $6205(54)$ & I.8 (2.0) \\
\hline \multicolumn{3}{|l|}{ Age $\dagger$} \\
\hline $5^{0-59}$ & $4 \mathrm{I} 66(37)$ & $\mathrm{I} .5(2.0)$ \\
\hline $6 o-69$ & $3399(28)$ & I.4 (I.8) \\
\hline $70-79$ & $2565(22)$ & I.8 $(2.0)$ \\
\hline $80+$ & I262 (I2) & 2.I (2.I) \\
\hline \multicolumn{3}{|l|}{ Economic activity $\dagger$} \\
\hline Employed (including self-employed) & $3607(32)$ & I.2(I.7) \\
\hline Retired (including semi-retired) & $5775(50)$ & I.6 (I.9) \\
\hline Home-maker & IO92 (IO) & I.8 (2.I) \\
\hline Unemployed/other economically inactive & $863(8)$ & $2.9(2.4)$ \\
\hline \multicolumn{3}{|l|}{ Total wealth quintile $\dagger$} \\
\hline I (least wealthy) & $2224(20)$ & $2.0(2 . \mathrm{I})$ \\
\hline 2 & $2240(20)$ & I.8 (2.0) \\
\hline 3 & $2277(20)$ & I.6(2.0) \\
\hline 4 & $2259(20)$ & I.5 (I.9) \\
\hline 5 (most wealthy) & $2292(20)$ & I.I (I.6) \\
\hline \multicolumn{3}{|l|}{ Marital status $\dagger$} \\
\hline Married/cohabiting & $7570(66)$ & I. $4(\mathrm{I} .8)$ \\
\hline Never married & $630(6)$ & I.6 (2.I) \\
\hline Widowed & I994 (I8) & $2.0(2 . \mathrm{I})$ \\
\hline Separated/divorced & II96 (Iо) & $2.0(2.3)$ \\
\hline
\end{tabular}

Note: SD: standard deviation.

Significance level: $\uparrow p<0.001$.

\section{Results}

In this cohort of community-dwelling adults aged 50 and over, there was a higher proportion of women than men and sizeable proportions of retired and widowed people (Table I).

The mean number of symptoms was higher for women and showed a U-shaped relationship with age, being the lowest for those in the 6o-69 age bracket. Unemployed participants and those in the lowest wealth quintile (the least wealthy) had a higher mean number of symptoms, as did those who were widowed or separated/divorced.

Participants endorsed statements which indicated reasonably high levels of neighbourhood social cohesion but were slightly less positive about perceived safety (Table 2 ). 
T A в L E 2. Measurement model for all latent factors simultaneously included

\begin{tabular}{|c|c|c|}
\hline & $\begin{array}{c}\text { Endorsing } \\
\text { statement }(\%)\end{array}$ & $\begin{array}{l}\text { Standardised } \\
\text { factor loading }\end{array}$ \\
\hline \multicolumn{3}{|l|}{ Neighbourhood social cohesion $\left(\mathrm{F}_{\mathrm{I}}\right)$ : } \\
\hline I really feel part of this area & $66^{1}$ & 0.57 \\
\hline Most people in this area can be trusted & $59^{1}$ & 0.69 \\
\hline Most people in this area are friendly & $70^{1}$ & 0.75 \\
\hline People in this area will always treat you fairly & $62^{1}$ & $0.6 \mathrm{I}$ \\
\hline \multicolumn{3}{|l|}{ Neighbourhood perceived safety $\left(\mathrm{F}_{2}\right)$ : } \\
\hline There is no problem with vandalism and graffiti in this area & $4^{6^{1}}$ & 0.64 \\
\hline People feel safe walking alone in this area after dark & $43^{1}$ & 0.47 \\
\hline $\begin{array}{l}\text { If you were in trouble, there are lots of people } \\
\text { in this area who would help you }\end{array}$ & $59^{1}$ & 0.67 \\
\hline \multicolumn{3}{|l|}{ Positive aspects of friendships $\left(\mathrm{F}_{3}\right)$ : } \\
\hline $\begin{array}{l}\text { How much do they really understand the way you feel about } \\
\text { things? }\end{array}$ & $78^{2}$ & 0.75 \\
\hline How much can you rely on them if you have a serious problem? & $8 \mathrm{I}^{2}$ & 0.80 \\
\hline $\begin{array}{l}\text { How much can you open up to them if you need to talk about } \\
\text { your worries? }\end{array}$ & $72^{2}$ & 0.85 \\
\hline \multicolumn{3}{|l|}{ Negative aspects of friendships $\left(\mathrm{F}_{4}\right)$ : } \\
\hline How much do they criticise you? & $12^{2}$ & 0.55 \\
\hline How much do they let you down when you are counting on them? & $12^{2}$ & 0.57 \\
\hline How much do they get on your nerves? & $7^{2}$ & 0.75 \\
\hline \multicolumn{3}{|l|}{ Personal sense of control $\left(\mathrm{F}_{5}\right)$ : } \\
\hline My age prevents me from doing the things I would like to $(\mathrm{R})$ & $37^{3}$ & 0.85 \\
\hline I feel that what happens to me is out of my control $(R)$ & $25^{3}$ & 0.82 \\
\hline I feel free to plan for the future & $8 \mathrm{I}^{3}$ & 0.47 \\
\hline I feel left out of things $(\mathrm{R})$ & $23^{3}$ & 0.89 \\
\hline \multicolumn{3}{|l|}{ Correlations between latent variables: } \\
\hline Cohesion with safety & & $0.6 \mathrm{I}$ \\
\hline Positive aspects of friendships with cohesion & & 0.23 \\
\hline Positive aspects of friendships with safety & & 0.12 \\
\hline Negative aspects of friendships with cohesion & & -0.27 \\
\hline Negative aspects of friendships with safety & & -0.17 \\
\hline Negative aspects of friendships with positive aspects of friendships & & $-0.2 \mathrm{I}$ \\
\hline Personal control with cohesion & & 0.29 \\
\hline Personal control with safety & & 0.29 \\
\hline Personal control with positive aspects of friendships & & 0.23 \\
\hline Personal control with negative aspects of friendships & & $-0.3^{\mathrm{I}}$ \\
\hline \multicolumn{3}{|l|}{ Model fit statistics: } \\
\hline SRMR & \multicolumn{2}{|c|}{0.052} \\
\hline RMSEA & \multicolumn{2}{|c|}{0.048} \\
\hline TLI & \multicolumn{2}{|c|}{0.9 II } \\
\hline
\end{tabular}

Notes: I. Percentage endorsing boxes 6 or 7 (highest agreement with statement). 2. Percentage endorsing boxes 'A lot' or 'Some'. 3. Percentage endorsing boxes 'Often' or 'Sometimes'. R: reverse coded. SRMR: Standardised Root Mean Squared Residual. RMSEA: Root Mean Square Error of Approximation. TLI: Tucker-Lewis Index.

Positive aspects of friendships were endorsed more frequently than were negative aspects. The latent variables are summarised in Table 2. The measurement model for the five latent variables 
T A B L E 3. Model estimates and goodness-of-fit indices for structural model for neighbourhood social environment as a predictor of number of depressive symptoms

\begin{tabular}{lccc}
\hline $\begin{array}{l}\text { Number of depressive symptoms at } \\
\text { wave 2 on }\end{array}$ & $\begin{array}{c}\text { Regression } \\
\text { coefficient (SE) }\end{array}$ & $\begin{array}{c}\text { Standardised } \\
\text { coefficient }\end{array}$ & $p$ value \\
\hline Neighbourhood social cohesion & $-0.158(0.044)$ & -0.070 & $<0.05$ \\
Perceived safety & $-0.030(0.03 \mathrm{I})$ & -0.019 & 0.3 \\
Male (reference female) & $-0.260(0.038)$ & -0.066 & $<0.00 \mathrm{I}$ \\
Age (per year increase) & $0.016(0.003)$ & 0.083 & $<0.00 \mathrm{I}$ \\
Retired (reference employed) & $-0.003(0.05 \mathrm{I})$ & $-0.00 \mathrm{I}$ & 0.9 \\
Unemployed (reference employed) & $0.565(0.090)$ & 0.076 & $<0.00 \mathrm{I}$ \\
Homemaker (reference employed) & $0.057(0.075)$ & 0.009 & $<.4$ \\
Separated/divorced (reference & $0.245(0.065)$ & 0.038 & $<0.00 \mathrm{I}$ \\
married) & & & \\
Widowed (reference married) & $0.056(0.058)$ & $0.01 \mathrm{I}$ & 0.3 \\
Never married (reference married) & $0.063(0.082)$ & 0.007 & 0.4 \\
Wealth (per quintile increase) & $-0.015(0.012)$ & -0.012 & $<.2$ \\
Number of depressive symptoms at wave I & $0.489(0.012)$ & 0.494 & $<0.00 \mathrm{I}$ \\
(per one symptom increase) & & & \\
Model fit statistics & & & \\
$\quad$ SRMR & & 0.037 & \\
RMSEA & & 0.043 & \\
TLI & & $0.83 \mathrm{I}$ & \\
\hline
\end{tabular}

Note: SE: standard error. SRMR: Standardised Root Mean Squared Residual. RMSEA: Root Mean Square Error of Approximation. TLI: Tucker-Lewis Index.

together showed acceptable fit to the data on the SRMR and RMSEA although the TLI indicated some lack of fit. Factor loadings were $>0.50$ for all items, with the exception of one item (' $\mathrm{I}$ feel free to plan for the future') on the personal sense of control factor. Because this item has been included in previous studies using the CASPig, we elected to retain it here. Neighbourhood social cohesion and perceived safety were moderately correlated $($ rho $=0.6 \mathrm{I})$ and other correlations between latent variables were around 0.20 or below.

The initial structural model is summarised in Table 3. Greater neighbourhood social cohesion was associated with fewer depressive symptoms, over and above gender, age, employment status, wealth, marital status and depressive symptoms at previous wave. The standardised coefficients indicate the relative importance of each predictor in the model whereas the unstandardised coefficients are interpreted as regression coefficients in the usual way. Each one unit increase in neighbourhood social cohesion is associated with a $0.15^{8}$ decrease in depressive symptoms. The standardised coefficients indicate that a one standard deviation increase in neighbourhood social cohesion is 
T A B L E 4. Model estimates and goodness-of-fit indices for full structural model including mediators

\begin{tabular}{|c|c|c|c|}
\hline & $\begin{array}{l}\text { Regression } \\
\text { coefficient (SE) }\end{array}$ & $\begin{array}{c}\text { Standardised } \\
\text { coefficient }\end{array}$ & $p$ value \\
\hline \multicolumn{4}{|l|}{ Negative aspects of friendships on: ${ }^{1}$} \\
\hline Neighbourhood social cohesion & -0.067 (0.01I) & 0.152 & $<0.001$ \\
\hline Perceived safety & $-0.001(0.008)$ & 0.003 & 0.9 \\
\hline \multicolumn{4}{|l|}{ Personal sense of control on: ${ }^{1}$} \\
\hline Neighbourhood social cohesion & $0.100(0.015)$ & 0.140 & $<$ o.oOI \\
\hline Perceived safety & o.016 (0.010) & 0.032 & O.I \\
\hline \multicolumn{4}{|c|}{ Number of depressive symptoms at wave 2 on: ${ }^{1}$} \\
\hline Negative aspects of friendships & $0.176(0.070)$ & 0.034 & o.OI \\
\hline Personal sense of control & $-0.858(0.063)$ & -0.268 & $<0.001$ \\
\hline Neighbourhood social cohesion & $-0.029(0.029)$ & -0.013 & 0.5 \\
\hline Perceived safety & $-0.02 \mathrm{I}(0.029)$ & -0.013 & 0.5 \\
\hline \multicolumn{4}{|l|}{ Model fit statistics } \\
\hline SRMR & \multicolumn{2}{|c|}{0.049} & \\
\hline RMSEA & \multirow{2}{*}{\multicolumn{2}{|c|}{0.044}} & \\
\hline TLI & & & \\
\hline
\end{tabular}

Notes: I. Number of depressive symptoms is additionally regressed on gender, age, employment status, marital status, wealth and number of depressive symptoms at wave I (estimates available from author on request). SE: standard error. SRMR: Standardised Root Mean Squared Residual. RMSEA: Root Mean Square Error of Approximation. TLI: Tucker-Lewis Index.

of similar effect size to a one year increase in age or to being unemployed.

In bivariate models (not shown), greater positive aspects of friendships, fewer negative aspects of friendships and greater personal sense of control were associated with reporting fewer depressive symptoms. However, positive aspects of friendships were not associated with depressive symptoms independently of the other mediators and were not included in subsequent models. In the full model (Table 4), fewer negative aspects of friendships and greater personal sense of control were found among participants who reported higher neighbourhood social cohesion and these intermediate variables fully mediated the association between neighbourhood social cohesion and depressive symptoms (Figure I). The standardised total effect of neighbourhood social cohesion on number of depressive symptoms at wave 2 was -0.056 . The indirect effect, acting through negative aspects of friendships and personal sense of control was - 0.043, leaving a direct effect of - o.or3. Although the SRMR and RMSEA indicate good fit to the data, the TLI suggests that improvements could be made and so the final model must be interpreted with this in mind. 


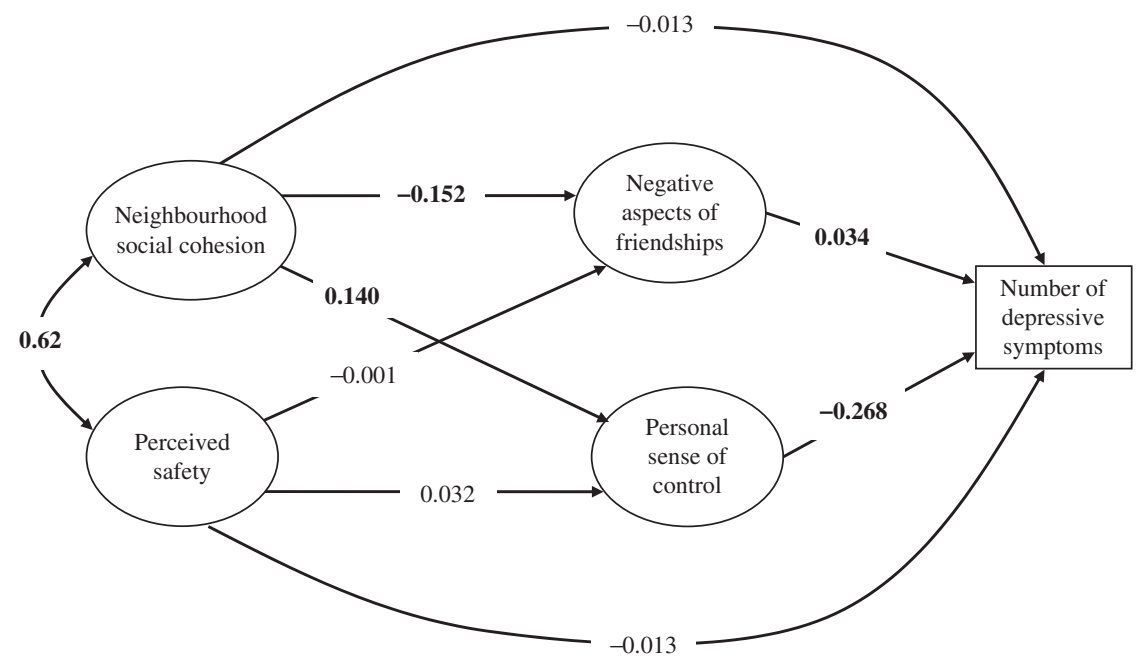

Figure I. Mediators of the association between neighbourhood social environment and depressive symptoms: standardised coefficients. Bold figures indicate $p<0.05$.

\section{Discussion}

In this longitudinal follow-up study of community-dwelling adults aged $5^{0}$ and over, neighbourhood social cohesion was found to be associated with subsequent depressive symptoms independent of demographic and socioeconomic factors and baseline depressive symptoms. Negative aspects of relationships with friends and personal sense of control were strongly associated with neighbourhood social cohesion and also with fewer depressive symptoms and fully mediated this association.

Before discussing these findings in more detail, some important methodological limitations must be noted. Depressive symptoms were selfreported (though extensively validated in several previous studies), as were the measures of quality of friendships, personal sense of control and neighbourhood social environment. Same source bias might therefore account for some of the associations seen and it is not possible to rule out personality or other unmeasured characteristics as drivers of the association between neighbourhood environment and depressive symptoms. However, adjustment for prior depressive symptoms should reduce the extent to which this biases the analysis. We find that, conditional on wave I depressive symptoms, those reporting lower neighbourhood social cohesion were more likely to report depressive symptoms at two-year follow-up. Furthermore, the direction of the association between neighbourhood social environment and friendship quality or 
personal sense of control cannot be inferred from these analyses which used wave I measures.

Items capturing the quality of friendships were not limited to friends in the neighbourhood and this probably dilutes the estimated association between neighbourhood factors and friendship quality. Omitted characteristics of the neighbourhood, such as residential mobility, deterioration, deprivation or affluence (Krause 2006), may confound the relationships seen here. Alternatively, these structural characteristics may be viewed as determinants of neighbourhood social cohesion itself (Wen, Browning and Cagney 2003). In either scenario, it is important to remember that environments characterised by low social cohesion are likely to be multiply disadvantaged on several indicators.

\section{Discussion of main findings}

The study adds to a growing literature testing associations between sociocultural characteristics in the neighbourhood and common mental disorders including depressive symptoms. A recent review concluded that there is evidence for an inverse association between constructs such as neighbourhood-based trust, solidarity and reciprocity measured at the individual level and depressive symptoms but highlighted a preponderance of cross-sectional studies which are unable to assess the temporality of the association (De Silva et al. 2005). Our findings based on longitudinal data indicate that neighbourhood social cohesion may be relevant for the development of depressive symptoms in older adults and are in line with previous studies. Mair et al. (2009) found that a summary neighbourhood score based on social cohesion along with violence and aesthetic environment was associated cross-sectionally with CES-D score but not with incident depression in a sample that included participants from 45 to 84 years of age. However, neighbourhood scores did differ in the expected direction for those who did and did not develop depression through follow-up and the odds ratios for women were suggestive of a protective association. A study of older Australians found a positive, unadjusted correlation between a scale comprising items capturing social cohesion (which they referred to as sense of neighbourhood) and mental health on the SF-36 (Young, Russell and Powers 2004).

The explanatory pathways underlying this relationship were also explored as part of this study. Socially cohesive environments are thought to be more conducive to supportive social relations. Summarising Kawachi and Berkman's (2001 $a$ ) work linking egocentric ties to the wider social context, Phillips writes 'Trusting social environments in turn tend to beget trustworthy citizens' (2006:203). Although previous studies have proposed 
social support as one of the potential mechanisms linking the neighbourhood social environment to mental health (Berkman et al. 2000), this has seldom been empirically tested. Elliott (2000) showed that social support, personal sense of control and social integration mediated the relationship between socioeconomic position and depression and interestingly found that social integration was protective for depression only in less disadvantaged neighbourhoods and sense of control appeared to afford greater protection against depression in more disadvantaged neighbourhoods. That study, along with another that found the association between neighbourhood problems and depressive symptoms was moderated by social support received (Schieman and Meersman 2004), suggests that further refinement of the current model may be appropriate, for example allowing the explanatory pathways linking social cohesion to depressive symptoms to vary according to neighbourhood type. Our findings suggest that neighbourhood social cohesion has implications for residents' individual psychosocial factors (sense of control and friendship quality) and for symptoms of depression. However, given the self-reported nature of the exposures and outcome, we must interpret the findings with caution. Multilevel studies linking true contextual measures of the neighbourhood social environment are needed, although such studies would have their own set of limitations around how to define the appropriate neighbourhood and whether residents truly agree on how they experience that neighbourhood.

\section{Implications for future research and policy}

Our findings show that negative aspects of friendships, lower personal sense of control and more depressive symptoms are more commonly experienced by people who perceive their neighbourhood to be low in social cohesion. One implication of this is that improvements in neighbourhood social cohesion might play a role in reducing the experience of negative social encounters and depression symptomatology. Exploration of the factors which shape social cohesion is beyond the scope of this study and is clearly a complex issue requiring careful consideration of the socioeconomic and political context, state institutions and social infrastructure (Baum 2000; Lynch et al. 2000; Szreter and Woolcock 2004).

This work is based on one of the largest longitudinal samples of community-living middle-aged and older people and has an important message about the health and wellbeing of older people in England's ageing population. Future work is needed to tease out health effects of the neighbourhood social environment according to different ages. Whilst it is possible that the young-old spend more time in and around their 
neighbourhood compared with working-age adults, it is possible that the oldest-old are more physically constrained, or choose to focus on a narrower set of intimate social ties (Carstensen, Isaacowitz and Charles i999) and spend the majority of their time in the home. For the latter group, the neighbourhood might assume less importance. The relationships between neighbourhood-based characteristics and friendships, control and health might therefore vary according to age among older people. This should be explored in future studies.

\section{Conclusion}

This prospective study links neighbourhood social cohesion to depressive symptoms through friendship quality and personal sense of control. It indicates that the perceived neighbourhood social environment may influence the quality of an older resident's friendships and that less negative aspects of friendships are reported by those who perceive their environment to be characterised by trust, solidarity and reciprocity. Future work might attempt to replicate the findings in other cohorts, using neighbourhood-level indicators and examining alternative explanatory pathways.

\section{Acknowledgements}

The data were made available through the UK Data Archive. The English Longitudinal Study of Ageing was developed by a team of researchers based at University College London, the Institute of Fiscal Studies and the National Centre for Social Research. The funding is provided by the National Institute on Aging in the United States (grants 2 ROIAG7644-orAI and 2 ROIAGor7644) and a consortium of UK government departments coordinated by the Office for National Statistics. The developers and funders of ELSA and the Archive do not bear any responsibility for the analyses or interpretations presented here.

\section{References}

Almedom, A. M. 2005. Social capital and mental health: an interdisciplinary review of primary evidence. Social Science and Medicine, 6r , 5, 943-64.

Aneshensel, C. and Sucoff, C. A. I996. The neighbourhood context of adolescent mental health. Fournal of Health and Social Behavior, 37, 4, 293-310.

Baltes, M. M., Maas, I., Wilms, H.-U., Borchelt, M. and Little, T. I999. Everyday competence in old and very old age: theoretical considerations and empirical findings. In Baltes, P. B. and Mayer, K. U. (eds) The Berlin Aging Study. Cambridge University Press, Cambridge, 384-402.

Banks, J., Karlsen, S. and Oldfield, Z. 2003. Socio-economic position. In Marmot, M., Banks, J., Blundell, R., Lessof, C. and Nazroo, J. (eds) Health, Wealth and Lifestyles of the 
Older Population in England: The 2002 English Longitudinal Study of Ageing, Institute for Fiscal Studies, London, 7I-I25.

Baum, F. 2000. Social capital, economic capital and power: further issues for a public health agenda. Fournal of Epidemiology and Community Health, 54, 6, 409-Io.

Berkman, L. F., Glass, T., Brissette, I. and Seeman, T. E. 2000. From social integration to health: Durkheim in the new millennium. Social Science and Medicine, 5I, 6, 843-57.

Boreham, R., Stafford, M. and Taylor, R. 2002. Health Survey for England 2000: Social Capital and Health. The Stationery Office, London.

Brown, G. W. and Harris, T. 1978. Social Origins of Depression: A Study of Psychiatric Disorder in Women. Free Press, New York.

Cannuscio, C., Block, J. and Kawachi, I. 2003. Social capital and successful aging: the role of senior housing. Annals of Internal Medicine, I 39, 5, 395-99.

Carstensen, L., Isaacowitz, D. and Charles, S. T. I999. Taking time seriously: a theory of socioemotional selectivity. American Psychologist, 54, 3, I65-8I.

Castro-Costa, E., Dewey, M., Stewart, R., Banerjee, S., Huppert, F., Mendonca-Lima, C., Bula, C., Reisches, F., Wancata, J., Ritchie, K., Tsolaki, M., Mateos, R. and Prince, M. 2007. Prevalence of depressive symptoms and syndromes in later life in ten European countries: the SHARE study. British Fournal of Psychiatry, I 91, 5, 393-40I.

Chou, K. L. 2005. Everyday competence and depressive symptoms: social support and sense of control as mediators or moderators? Aging \& Mental Health, 9, 2, 177-83.

De Silva, M. J., McKenzie, K., Harpham, T. and Huttly, S. R. A. 2005. Social capital and mental illness: a systematic review. Fournal of Epidemiology and Community Health, 59, 8, 6 I9-27.

Ellaway, A., Macintyre, S. and Kearns, A. 200r. Perceptions of place and health in socially contrasting neighborhoods. Urban Studies, 38, I2, 2299-316.

Ellaway, A., Morris, G., Curtice, J., Robertson, C., Allardice, G. and Robertson, R. 2009. Associations between health and different types of environmental incivility: a Scotlandwide study. Public Health, I 23, II, 708-13.

Elliott, M. 2000. The stress process in neighborhood context. Health and Place, 6, 4, 287-99.

Erens, B. and Primatesta, P. 1999. Health Survey for England 1998. Volume 2, Methodology and Documentation. London: HMSO.

Fyrand, L., Moum, T., Finset, A. and Glennas, A. 2002. The impact of disability and disease duration on social support of women with rheumatoid arthritis. Fournal of Behavioral Medicine, 25, 3, 25 I-68.

Hawe, P. and Shiell, A. 200o. Social capital and health promotion: a review. Social Science and Medicine, 5I, 6, 7I-85.

Hobfoll, S. E. and Stephens, M. A. P. I99o. Social support during extreme stress: consequences and intervention. In Sarason, B. R., Sarason, I. G. and Pierce, G. R. (eds) Social Support: An Interactional View. John Wiley, New York, 454-8I.

House, J. S., Landis, K. R. and Umberson, D. ig88. Social relationships and health. Science, 24I, 4865, 540-4.

Hu, L. and Bentler, P. M. I999. Cutoff criteria for fit indexes in covariance structure analysis: conventional criteria versus new alternatives. Structural Equation Modeling, 6, I, I-55.

Hyde, M., Wiggins, R. D., Higgs, P. and Blane, D. B. 2003. A measure of quality of life in early old age: the theory, development and properties of a needs satisfaction model (CASP-r9). Aging \& Mental Health, 7, 3, I86-94.

Ingersoll-Dayton, B., Morgan, D. and Antonucci, T. 1997. The effects of positive and negative social exchanges on aging adults. Fournals of Gerontology: Social Sciences, 52, 4, Sigo-9.

Kawachi, I. and Berkman, L. F. 2001 $a$. Social ties and mental health. Fournal of Urban Health, 78, 3, 458-67. 
Kawachi, I. and Berkman, L. F. 2001 $b$. Social cohesion, social capital and health. In Berkman, L. F. and Kawachi, I. (eds) Social Epidemiology. Oxford University Press, Oxford, I74-190.

Keating, N., Swindle, J. and Foster, D. 2005. The role of social capital in aging well. In Frank, J. (ed.) Social Capital in Action: Thematic Policy Studies. Policy Research Initiative, Ottawa, 24-48.

Keeton, C. P., Perry-Jenkins, M. and Sayer, A. G. 2008. Sense of control predicts depressive and anxious symptoms across the transition to parenthood. Fournal of Family Psychology, 22, 2, 212-21.

Kim, D. 2008. Blues from the neighborhood? Neighborhood characteristics and depression. Epidemiologic Reviews, 30, I, IOI-I7.

Krause, N. 2006. Neighborhood deterioration, social skills, and social relationships in late life. International Fournal of Aging and Human Development, 62, 3, I85-207.

Laporte, A., Nauenberg, E. and Shen, L. 2007. Aging, social capital, and health care utilization in Canada. Health Econcomics, Policy and Law, 3, 4, 393-4II.

Lawton, M. P. I99o. Residential environment and self-directedness among older people. American Psychologist, 45, 5, 638-40.

Lin, N., Ye, X. and Ensel, W. M. r999. Social support and depressed mood: a structural analysis. Fournal of Health and Social Behavior, 4o, 4, 344-359.

Lynch, J., Due, P., Muntaner, C. and Davey Smith, G. 200o. Social capital - is it a good investment strategy for public health?. Fournal of Epidemiology and Community Health, 54, 6, 404-8.

Mair, G., Diez Roux, A. V., Shen, M., Shea, S., Seeman, T., Echeverria, S. and O’Meara, E. S. 2009. Cross-sectional and longitudinal associations of neighborhood cohesion and stressors with depressive symptoms in the multiethnic study of atherosclerosis. Annals of Epidemiology, I 9, I, 49-57.

Martin, K. R., Shreffler, J., Schoster, B. and Callahan, L. F. 2010. Associations of perceived neighborhood environment on health status outcomes in persons with arthritis. Arthritis Care \& Research. Available online at http://onlinelibrary.wiley.com/doi/ I0.IO02/acr.20267/pdf [Accessed i3 October 2010].

McMunn, A., Nazroo, J., Wahrendorf, M., Breeze, E. and Zaninotto, P. 2009. Participation in socially productive activities, reciprocity and wellbeing in later life: Baseline results in England. Ageing \& Society, 29, 5, 765-82.

Murray, C. J. and Lopez, A. D. 1996. The global Burden of Disease: A Comprehensive Assessment of Mortality and Disability from Disease, Injuries and Risk Factors in I99o. Harvard School of Public Health on behalf of the World Bank, Boston, Massachusetts.

Pevalin, D. J. and Rose, D. 2003. Social Capital for Health. Investigating the Links Between Social Capital and Health Using the British Household Panel Survey. Health Development Agency, London.

Phillips, D. 2006. Quality of Life: Concept, Policy and Practice. Routledge, London.

Phongsavan, P., Chey, T., Bauman, A., Brooks, R. and Silove, D. 2006. Social capital, socio-economic status and psychological distress among Australian adults. Social Science and Medicine, 63, I0, 2546-6r.

Pollack, C. and von dem Knesebeck, O. 2004. Social capital and health among the aged: comparisons between the United States and Germany. Health \& Place, ro, 4, 383-9I.

Portes, A. 1998. Social capital: its origins and applications in modern sociology. Annual Review of Sociology, 24, I, I-24.

Rauktis, M. E., Koeske, G. F. and Tereshko, O. I995. Negative social interactions, distress, and depression among those caring for a seriously and persistently mentally ill relative. American Fournal of Community Psychology, 23, 2, 279-99.

Rodin, J. I986. Aging and health: Effects of the sense of control. Science, 233, I27I-6. 
Roman, C. G. and Chalfin, A. 2008. Fear of walking outdoors. A multilevel ecologic analysis of crime and disorder. American Fournal of Preventive Medicine, 34, 4, 306-I2.

Ross, C. E. 2000. Neighborhood disadvantage and adult depression. Fournal of Health and Social Behavior, 4I, 2, I77-87.

Ross, G. E. and Mirowsky, J. 20o6. Sex differences in the effect of education on depression: resource multiplication or resource substitution? Social Science and Medicine, 63, 5, I400-I3.

Rubinstein, R. L. and Parmelee, P. A. 1992. Attachment to place and the representation of the life course by the elderly. In Altman, I. and Low, S. M. (eds) Place Attachment. Plenum, New York, I39-63.

Sampson, R. J. I988. Local friendship ties and community attachment in mass society: a multi-level systematic model. American Sociological Review, 53, 5, 766-79.

Sampson, R. J., Raudenbush, S. W. and Earls, F. 1997. Neighborhoods and violent crime: a multilevel study of collective efficacy. Science, 277, 5328, 918-24.

Scharf, T., Phillipson, C. and Smith, A. 2003. Older people's perceptions of the neighbourhood: evidence from socially deprived urban areas. Sociological Research Online, 8, 4. Available online at http://www.socresonline.org.uk/8/4/scharf.html [Accessed I4 June 2009].

Scheffler, R. M., Brown, T. T. and Rice, J. K. 2007. The role of social capital in reducing non-specific psychological distress: the importance of controlling for omitted variable bias. Social Science and Medicine, 65, 4, 842-54.

Schieman, S. and Meersman, S. C. 2004. Neighborhood problems and health among older adults: received and donated social support and the sense of mastery as effect modifiers. Fournals of Gerontology: Social Sciences, 59B, 2, S89-97.

Shah, A. 1992. The burden of psychiatric disorder in primary care. International Review of Psychiatry, 4, 33, 243-50.

Shenk, D., Kuwahara, K. and Zablotsky, D. 2004. Older women's attachments to their home and possessions. Fournal of Aging Studies, 18, 2, I57-69.

Stafford, M., Chandola, T. and Marmot, M. 2007. Fear of crime is associated with poor mental health and limited physical functioning. American Fournal of Public Health, 97, II, $2076-81$.

Stansfeld, S. and Candy, B. 2006. Psychosocial work environment and mental health - a meta-analytic review. Scandinavian Fournal of Work, Environment and Health, 32, 6, $443^{-62 .}$

Stansfeld, S. A., Fuhrer, R. and Shipley, M. J. 1998. Types of social support as predictors of psychiatric morbidity in a cohort of British civil servants (Whitehall II study). Psychological Medicine, 28, 4, 88I-92.

Steptoe, A., Tsuda, A., Tanaka, Y. and Wardle, J. 2007. Depressive symptoms, socioeconomic background, sense of control, and cultural factors in university students from 23 countries. International Fournal of Behavioural Medicine, 14, 2, 97-107.

Szreter, S. and Woolcock, M. 2004. Health by association? Social capital, social theory, and the political economy of public health. International fournal of Epidemiology, 33, 4, $650-67$.

Taylor, R., Conway, L., Calderwood, L., Lessof, C., Cheshire, H., Cox, C. and Scholes, S. 2003. Health, Wealth and Lifestyles of the Older Population in England. The 2002 English Longitudinal Study of Ageing. National Centre for Social Research, London.

Turvey, C. L., Schultz, S. K., Beglinger, L. and Klein, D. M. 2009. A longitudinal community-based study of chronic illness, cognitive and physical function, and depression. American Fournal of Geriatric Psychiatry, I 7, 8, 632-4I.

Turvey, C., Wallace, R. and Herzog, R. I999. The relation between a revised CES-D measure of depressive symptoms and a DSM-based measure of major depressive episodes in the elderly. International Psychogeriatrics, I I, 2, 139-48. 
Van der Horst, R. K. and McLaren, S. 2005. Social relationships as predictors of depression and suicidal ideation in older adults. Aging and Mental Health, 9, 6, 517-25.

Wen, M., Browning, C. R. and Cagney, K. A. 2003. Poverty, affluence, and income inequality: neighborhood economic structure and its implications for health. Social Science and Medicine, 57, 5, 843-6o.

Wilson, J. Q. and Kelling, G. L. 1982. Broken windows: the police and neighborhood safety. Atlantic Monthly, March. Available online at http://www.manhattan-institute. org/pdf/_atlantic_monthly-broken_windows.pdf [Accessed i7 September 2010].

Xue, Y., Leventhal, T., Brooks-Gunn, J. and Earls, F. J. 2005. Neighborhood residence and mental health problems of 5- to in-year-olds. Archives of General Psychiatry, 62, 5, $554^{-63}$.

Yang, Y. 2006. How does functional disability affect depressive symptoms in late life? The role of perceived social support and psychological resources. Fournal of Health and Social Behavior, 47, 4, 355-72.

Young, A. F., Russell, A. and Powers, J. R. 2004. The sense of belonging to a neighbourhood: can it be measured and is it related to health and well being in older women? Social Science and Medicine, 59, I2, 2627-37.

Accepted 15 October 20IO; first published online 20 January $201 \mathrm{I}$

Address for correspondence:

Mai Stafford, MRC Unit for Lifelong Health and Ageing, 33 Bedford Place, London WGiB $55 \mathrm{JU}$, UK.

E-mail: m.stafford@nshd.mrc.ac.uk 